\title{
Journeys from discomfort to comfort: how do university students experience being taught and assessed by adults with intellectual disabilities?
}

\section{Michael Feely , Edurne Garcia Iriarte , Clare Adams, Ryan Johns , Christine} Magee, Sean Mooney , Andrew Murray , Margaret Turley \& Mei Lin Yap

To cite this article: Michael Feely , Edurne Garcia Iriarte , Clare Adams, Ryan Johns, Christine Magee , Sean Mooney, Andrew Murray, Margaret Turley \& Mei Lin Yap (2021): Journeys from discomfort to comfort: how do university students experience being taught and assessed by adults with intellectual disabilities?, Disability \& Society, DOI: 10.1080/09687599.2021.1874301

To link to this article: https://doi.org/10.1080/09687599.2021.1874301

\section{Published online: 29 Jan 2021.}

\section{Submit your article to this journal}

Џ Article views: 22

Q View related articles $\sqsubset$

View Crossmark data \lceil 


\title{
Journeys from discomfort to comfort: how do university students experience being taught and assessed by adults with intellectual disabilities?
}

\author{
Michael Feely, Edurne Garcia Iriarte (D), Clare Adams, Ryan Johns, \\ Christine Magee, Sean Mooney, Andrew Murray, Margaret Turley and \\ Mei Lin Yap
}

School of Social Work and Social Policy, Trinity College Dublin, Dublin, Ireland

\begin{abstract}
From 2016-17, academics at a leading Irish university collaborated with a group of self- advocates with intellectual disabilities to co-design, co-deliver, and co-assess an entire disability module for third-year undergraduate social work students. There are few, if any, reports of university modules of this type, involving adults with intellectual disabilities, in the existing literature. Alongside and after the module, our group of academics and self-advocates conducted inclusive research regarding relevant stakeholders' experiences of the initiative. This paper relates to university students' experiences of being taught and assessed by adults with intellectual disabilities. These experiences were overwhelmingly positive with reported benefits including increased comfort around disability and greater empathy with people with people with disabilities. This said, some aspects of being taught and assessed by self-advocates with intellectual disabilities also provoked considerable anxiety among students.
\end{abstract}

\section{ARTICLE HISTORY}

Received 13 December 2019 Accepted 12 December 2020

\section{KEYWORDS}

Intellectual disability; learning disability; university; inclusion; health and social care professional education

\section{Points of interest}

- From 2016 to 2017, academics at a leading Irish university collaborated with a group of self-advocates with intellectual disabilities to design, teach and mark a disability module for social work students.

- The group also conducted inclusive research regarding people's experiences of the module

- This paper explores how university students experienced being taught and marked by adults with intellectual disabilities. 
- Students' experiences were generally very positive. They said the module led to more empathy with disabled people and reduced their discomfort around disability

- At the same time, some aspects of the module, particularly the idea of being marked by adults with intellectual disabilities, made them very nervous.

- We hope that our research might encourage others to employ adults with intellectual disabilities as university lecturers and markers.

\section{Introduction}

From 2016 to 2017, two academics at a leading Irish University collaborated with a group of six self-advocates with intellectual disabilities to co-design, codeliver and co-assess a disability module for third-year undergraduate social work students. There are few reports of university modules of this type in the existing literature. Alongside and after the module, our group of academics and self-advocates conducted inclusive research about various stakeholders' experiences of the module. This paper focuses on undergraduate students' experiences. Our paper begins with a brief review of literature regarding the principle of participation and on including service users in health and social care education. We then move on to describe our inclusive teaching project and the methodology we adopted to study students' experiences of it. After this we present a thematic analysis of students' experiences. Our key findings are that students: welcomed the initiative but were anxious about how it might affect their grades; experienced the initiative as helpful in alleviating their discomfort around disability; recognised and valued how the initiative created powerful roles for those with intellectual disabilities; came to acknowledge self-advocates as experts by experience and to accept them as qualified to assess university students; described how the initiative facilitated increased empathy with people with intellectual disabilities; and, finally, felt the module left them with an increased appreciation for what intellectually disabled people can achieve and a commitment to 'aim higher' in supporting their life goals. At this stage in the paper, we offer a discussion of our findings that draws upon both the existing literature and insights from members of our inclusive research team. We conclude by considering the significance of our findings for self-advocates with intellectual disabilities and those involved in health and social care education who may wish to introduce similar initiatives.

\section{Literature review}

Our literature review strategy involved a search of Psyclnfo, Eric, Web of Science and Google Scholar with search terms including: 'service user' AND 'social work education'; 'service user' AND 'health and social care education'; 
'intellectual disability' OR 'learning disability' AND 'social work education'; 'intellectual disability' OR 'learning disability' AND 'health and social care education'. Our findings are discussed here in relation to literature on the principle of participation and literature on including service users in general, and adults with intellectual disabilities in particular, in health and social care education

\section{The principle of participation}

Since at least the early 1990s the slogan 'Nothing About Us Without Us' has been embraced by disability activists within the disability rights movement (Charlton 1998). The slogan, of course, relates to the principle that people with disabilities should be involved in discourse relating to them and decisions affecting them.

The principle of participation has also become influential in the field of health and social care professional education where it relates not just to people with disabilities but rather the full range of groups that access services. Real value is now attached to service user participation in professional education (Fox 2011), and many academics in this field have suggested service users' experiences and expertise should be at the core of professionals' education (Repper and Breeze 2007; Simons et al. 2007; Stickley and Bassett 2007; Warren 2007). More recently, in 2016, a group of concerned academics and activists issued what they called The Vancouver Statement, to describe the current state of service user involvement and to identify goals for the next five years (Towle et al. 2016).

Contemporary policy regarding health and social care professional education also calls for meaningful service user involvement. For example, the International Association of Schools of Social Work (IASSW 2004) makes the inclusion of service users in Social Work education a standard. Meanwhile, CORU - the body that accredits social work programmes in Ireland - has similar requirements (CORU 2016).

On a broader level, relevant legislation has also embraced participation. In the UK, for example, the Equality Act 2010 enshrined the principle of service user engagement. Meanwhile, when Ireland finally ratified UN Convention on the Rights of Persons with Disabilities in 2018, it embraced a range of rights around participation and recognised that the full participation of persons with disabilities will result in... significant advances in the human, social and economic development of society' (CRPD Preamble).

\section{Including service users in health and social care professional education}

While consensus may exist regarding the importance of participation, to what extent, and how, this works in practice is less clear. In reviewing the 
literature, Spencer et al. (2001) suggest that participation is relatively widespread in social care and non-medical mental health professional training while patchier in medical disciplines. They also note that most initiatives described in the literature involve including service users in one aspect of a broader, non-inclusive curriculum. Also reviewing the literature, Repper and Breeze (2007) detail some of the methods of inclusion reported in the literature. These include: collecting service users' views and experiences to inform training; involving service users in the production of learning materials; involving service users as teaching aids; and including service users in the classroom through inviting representatives of a particular group of service users to share their life stories or to participate in aspects of assessment.

Numerous studies detail health and social care students' experiences of service user participation in education. These studies chronicle largely positive student experiences. More specifically, benefits are noted in areas including increased understanding, empathy, communication skills, and confidence. For example, in Costello and Horne (2001), nursing students report valuing the involvement of patients in a teaching session because it facilitated a deeper understanding of patients' perspectives; in Tanner et al. (2017) students students suggest the involvement of patients in a clinical interviewing workshop was valuable in enhancing feelings of emotional connection and empathy; in Kelly and Wykurz (1998), undergraduate medical students report that sessions with patient partners fortified communication skills; and in Maughan, Finlay, and Webster (2001), medical students report that sessions involving cancer patients facilitated greater confidence in talking to patients with serious illnesses and gave them a better appreciation of service users strengths.

While the experiences detailed in studies like these are, overall, positive, it is possible to find accounts of more challenging experiences too. For example, in the Costello and Horne (2001) study, mentioned previously, students also described embarrassment when interacting with patients. Similarly, in Ottewill et al. (2006), alongside positive experiences, physiotherapy students reported anxiety during a session with stroke patients related to the unconventional nature of the experience. Meanwhile, social work students in Northern Ireland expressed concern about service user distress (Duffy, Das, and Davidson 2013).

\section{Including people with intellectual disabilities in health and social care professional education}

Literature regarding the inclusion of people with intellectual disabilities in health and social care education, and how this affects students' learning experiences, is scarce with only a handful of relevant sources. 
In an opinion piece, Biswas, Raju, and Gravestock (2009) discuss the inclusion of people with intellectual disabilities, and their carers, in psychiatry training. They note a gradual shift toward more service user involvement in this field over recent decades. They suggest that if included in a meaningful (rather than tokenistic) and egalitarian fashion, service users can share valuable knowledge with students concerning their experiences of medical/psychological conditions, the health care system and of interacting with professionals.

In this journal, Boxall, Carson, and Docherty (2004) explore people with learning disabilities' involvement in a Learning Disability Studies degree in Manchester. While not focusing in-depth on students' experiences of this, they do note that inclusive teaching prompted some students to reassess what they considered valid knowledge:

Before I joined this degree, I thought that knowledge only came from books and lecturers' mouths... Daniel [contributor to the programme with a learning disability] knows more about the subject than I do. I shouldn't be surprised by that, but I am' (student quoted in Boxall, Carson, and Docherty 2004, 106).

Bollard, Lahiff, and Parkes (2012) note a lack of studies regarding service user participation in professional education that relate specifically to people with learning disabilities, and go on to describe their efforts to include people with learning disabilities in multiple aspects of a new undergraduate nursing programme. Student responses to self-advocates' inputs were positive with reported benefits relating particularly to communication skills. They conclude that: 'the involvement of people with learning disabilities provides deep learning experiences for student nurses that they carry beyond their initial training' (Bollard, Lahiff, and Parkes 2012, 177).

Finally, in a rare but highly relevant study, Ward et al. (2016) describe an initiative in which Christian Raphael, a man with profound and multiple learning disabilities, was commissioned to design and deliver two days of teaching for social work students with a number of supporters. The experience proved particularly important in challenging students' restrictive assumptions about people with this type of disability:

This experience had had a profound impact on me ... and I will always remember how it is possible to achieve anything in life when you have people believe in you and show you genuine support (student in Ward et al. 2016, 928).

Having established that literature regarding the inclusion of adults with intellectual disabilities in health and social care education is scarce, we shall now proceed to outline our attempt at inclusion and students' reactions to this.

\section{About the project}

Over recent decades, a leading Irish university has sought to include adults with intellectual disabilities through initiatives such as a certificate 
programme for this population. This programme enables adults with intellectual disabilities to experience student life within a mainstream university. The project described in this paper - imagined initially by academics in the School of Social Work and Social Policy - aimed to break new ground by including adults with intellectual disabilities in academic life too. More specifically, two academics proposed working with a group of self-advocates to co-design, codeliver and co-assess an entire module on the topic of disability for third year undergraduate Social Work students as well as conducting inclusive research regarding the outcomes of the project. Our proposal was awarded a university teaching innovation award of $€ 15,000$. Self-advocates were recruited through a self-advocacy group supported by the lead researcher over recent years and through the previously mentioned certificate programme for adults with intellectual disabilities at the university. Eventually six self-advocates (three males and three females in their twenties) were offered co-lecturer roles. Our grant funding allowed us to offer self-advocates the same pay and conditions afforded to other sessional lecturers in the university. Self-advocates were also able to register as staff members and receive staff identity cards and associated privileges. Left over grant money was used to pay two of the selfadvocates to co-deliver the module with the main researcher the following year, in 2018. After a gap in 2019 (due to an academic sabbatical), the two self-advocates returned to co-lecturing in 2019. In the longer term, we plan to keep the initiative running for as long as we can secure funding.

The group of six self-advocates and two academics met regularly from August 2016 to January 2017 to discuss and plan the module curriculum. We agreed that all content should be understandable to everyone. In practice, this meant using lay language and pictures and eschewing standard academic referencing conventions in PowerPoint presentations, while suggesting further academic texts for students at the end of these presentations. The academic members of the team suggested some disability theory, policy and legislation that they felt students should be aware of, but we agreed that self-advocates would be involved in teaching these topics and would demonstrate their significance by sharing relevant life-stories or through role plays involving self-advocates and students. Self-advocates also suggested topics that were important to them, which they felt should be covered, including disability etiquette, their right to have intimate relationships, and their experiences of discrimination. Regarding assessing students, we agreed on standard academic group essays (worth $50 \%$ of the available marks) to be marked by the academics coupled with accessible group presentations, based on the essays, to be marked by the self-advocates (also worth $50 \%$ of the available marks).

Teaching consisted of twelve two-hour lecture sessions in traditional classrooms (with a capacity for 50 people), which ran from January to April 2016. 
The lectures generally involved a presentation by the self-advocates and academics on the main topic, using PowerPoint slides, presentations by selfadvocates on their personal experiences in relation to the main topic, and activities that encouraged active participation by students, such as small and big group discussions, and role plays. For two of the sessions, outside speakers were asked to, and agreed to, contribute, specifically a lady with cerebral palsy who spoke about the impact of the social model on her life and a father and his adult son with Down syndrome who spoke about using personalised budgets to create a rich and meaningful life.

When it came to assessment time, students were divided into groups of four and could choose between a traditional 3,000 word essay on the topic of competing models of disability and their implications for social work (a topic suggested by academics) or on barriers faced by people with intellectual disabilities who want to have intimate relationships (a topic of particular interest to self-advocates). After the academic essays were submitted, group presentations took place in the classroom over two weekly sessions. Groups had fifteen minutes to present the findings of their research essay and were advised by self-advocates to limit their use of text and to explore creative alternatives to make their findings accessible. In response to this request, student presentations took a variety of non-traditional forms including an animated short film, brief documentary videos, several plays, a short live action movie, a fairy tale that parodied Irish legislation around sexuality and disability and so on. A panel of self-advocates marked the presentations using plain language forms (see Figure 1) and a simplified marking system where excellent equated to $75 \%$, very good to $65 \%$, quite good to $55 \%$ and so on.

Regarding the results of the group essays and presentations, the marks students received for their academic essays tended to correlate closely with the marks they received for their accessible presentations (see Figure 2).

\section{Methodology}

This study used a qualitative research framework and an inclusive research approach in which academics and self-advocates were involved as co-lecturers and researchers. A qualitative methodology allowed the researchers to gather and make sense of social work students' experiences of the module. Inclusive research entails enquiring along with people with intellectual disabilities, who participate in the research process as partners (García Iriarte, O'Brien, and Chadwick 2014; Nind 2017; Walmsley, Strnadova, and Johnson 2018). Funding secured by academics did not cover research participation of self-advocates and therefore, they participated on a voluntary, non-paid basis, in the design, data collection (as participants in a focus group), data 


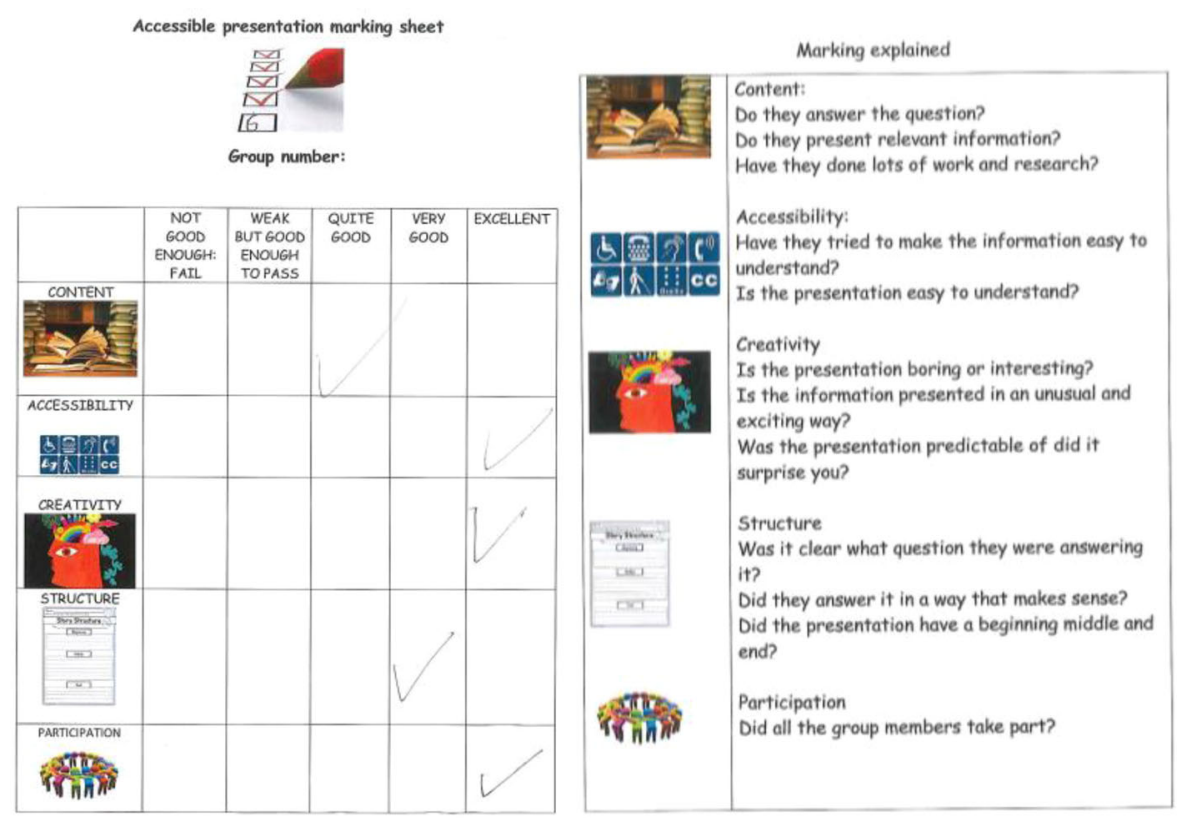

Figure 1. Accessible marking sheet and explanation.

\begin{tabular}{|l|l|l|}
\hline Student Group Number & $\begin{array}{l}\text { Academic Essay (Marked by } \\
\text { Academic Examiner) }\end{array}$ & $\begin{array}{l}\text { Accessible Presentation } \\
\text { (Marked by Self-Advocates } \\
\text { with Intellectual Disabilities) }\end{array}$ \\
\hline 1 & 67 & 66 \\
\hline 2 & 73 & 72 \\
\hline 3 & 70 & 71 \\
\hline 4 & 62 & 57 \\
\hline 5 & 66 & 67 \\
\hline 6 & 64 & 67 \\
\hline 7 & 65 & 70 \\
\hline 8 & 66 & 64 \\
\hline 9 & 61 & 59 \\
\hline 10 & 67 & 67 \\
\hline 11 & 68 & 67 \\
\hline
\end{tabular}

Figure 2. Marks awarded by academics and self-advocates.

analysis, and write up of findings. A research assistant was employed to conduct interviews and focus groups.

The academics had decided on a qualitative and inclusive research design at the grant application stage and submitted an ethics application before self-advocates were recruited. Collaborative work between academics and self-advocates took place through three sessions: a first session to explain the research design and the options for self-advocates to be involved as researchers; a second session to discuss who should conduct focus groups; and a third session to discuss and agree on the research questions for the focus group. 
The group had different opinions on who should conduct the focus group with students. One self-advocate strongly felt that self-advocates should facilitate the focus group because it was about students' experiences of being taught by self-advocates. Meanwhile one academic defended the idea that a focus group facilitated by someone else would provide more freedom to students to voice their experiences and avoid socially desirable responses. Despite the overwhelming positive feedback received informally from students, which would have minimised the risk of negative comments, another self-advocate agreed with the academic and it was decided that a research assistant with no involvement in the project would facilitate the focus groups. The research assistant chosen was a former social work student, mother of a young person with an intellectual disability, and employed in a non-government organisation advocating for the rights of persons with intellectual disabilities, which the self-advocates felt in alignment with their rights-based position. The focus group questions were developed with input from the academics, the research assistant, and self-advocates who thought it was important to know the research assistant in advance and to convey their views on what questions should be asked, and how, to students.

\section{Data collection methods}

Data collection was through a combination of anonymous questionnaires and a focus group. Anonymous questionnaires were distributed to students during the final session of the module and students were given time to answer a series of open-ended questions about how they experienced the module. In retrospect, we were unwise to wait until the last session of the module. At this stage, students had completed their assignments, had impending examinations, and were aware that the last session of our module would be reflective rather than covering new content. In these circumstances, we had, by far, our lowest student turnout. In total, eighteen students completed the questionnaires. Students were also given another form alongside the questionnaire, which asked if they would be interested in taking part in a focus group. The focus group aimed to gather the perspectives of students in a peer support context (Patton 2015) and involved four female students, ranging in age from twenty-one to fifty years, with an average of thirty-five. The focus group lasted seventy-two minutes and was recorded and transcribed verbatim with the participants' permission.

\section{Data analysis methods}

Thematic analysis was used to analyse the data as it enabled the researchers to understand the experiences of participants (Braun and Clarke 2006) and it 
has been successfully used with people with intellectual disabilities as coresearchers (Bane et al. 2012; García Iriarte, O'Brien, and Chadwick 2014; Kramer et al. 2011; Salmon et al. 2019). The main researcher conducted a preliminary analysis of the questionnaire and focus group data. Two inclusive analysis meetings were arranged in order to accommodate self-advocates' schedules (two self-advocates attended the first and three attended the second). At these meetings - using accessibly designed PowerPoint presentations - the main researcher shared several initial themes with quotes to self-advocates. Self-advocates' comments and quotes on these themes were collected and the themes were altered in line with these. Self-advocates' comments were also incorporated into the discussion section of this manuscript, which was written up by the two academics. In order to differentiate their voices, their comments have been formatted in italics (see Strnadova and Walmsley 2018).

\section{Findings}

In this section we present the themes identified through data analysis. Students who filled in the anonymous questionnaire have been assigned numbers (e.g. Anonymous 1). Focus group participants have also been assigned numbers to ensure anonymity (e.g. Focus group participant 1).

\section{Reactions to being taught and examined by self-advocates: 'would they be actually doing the teaching, or would they be the token people nodding at the side?'}

When asked how they felt upon learning they would be co-taught by adults with intellectual disabilities, the most common responses were related to excitement at being part of something new and different. For example:

Anonymous 13: When I found out the module was going to be co-lectured, it made it stand out from the other modules we were taking, and I looked forward to seeing what the lectures would be like each week.

Another response was curiosity around whether co-lecturing would work in practice and whether it would extend beyond tokenism:

Focus group participant 1: I just wondered would it be real. Would they be actually doing the teaching, or would they be the token people nodding at the side?

Some respondents also reported feelings of scepticism:

Anonymous 18: I suppose my preconceptions of intellectual disabilities and what it means made me think and feel negatively about the ability of the self-advocates to teach the content of this module.

This said, these participants were clear that their initial scepticism proved ill-founded: 
Anonymous 18: But, and it's a big but: how wrong I was! I thoroughly enjoyed each class.

While the prospect of being taught by adults with intellectual disabilities was, in general, greeted with enthusiasm, the dominant response to the prospect of being assessed by adults with intellectual disabilities was anxiety. Much of this anxiety was related to a perception amongst students that people with intellectual disabilities in general (or their assessors with intellectual disabilities in particular) had a capacity for brutal honesty. One student valued this honesty:

Anonymous 2: I know that we will get complete honest feedback on our work from the co-lectures and that will give me the ability to develop more.

However, for many, it was a source of apprehension. For example:

Anonymous 9: Because of this truthfulness I felt a little apprehensive that they would be hard markers of assessments!

One student's concern regarding their markers' honesty was compounded by the belief that - given the perceived egalitarian relationships between lecturers - non-disabled lecturers would not step in to overturn anomalous decisions by self-advocates:

Focus group participant 1: There was a little part of me that was thinking 'Well hold on we've worked really hard and I really want to get good marks. So, I thought, now they could just go 'Oh that's just brutal' and knowing the lecturers would go 'Oh well, if that's what you think, that's fine'. I was thinking there will be nobody there to say 'Ah no, that's really good. You need to ...'

Others had similar concerns about the marks self-advocates would give and how these would affect overall grades for the year. One student felt that this type of anxiety might have been particularly high amongst competitive, high-achieving peers:

Focus group participant 3: But say somebody that is very competitive and wants their first [highest mark], you know? How are they going to deal with (...) the fact that this, you know, is being academically marked and 'I want my first, is this going to somehow affect my overall mark?' (...) I think some people might have kind of had that.

While there was undoubtedly considerable anxiety at the prospect of assessment by self-advocates, this too seems to have proved ill-founded, as feedback regarding the actual experience of assessment was overwhelmingly positive. For example:

Anonymous 15: I enjoyed making the presentation accessible and loved watching their reactions to everyone's presentations. It was made very fair.

and 
Anonymous 5: I felt it was a really positive experience to be assessed by adults with intellectual disabilities.

To summarise, many students relished the prospect of being taught by self-advocates, but some were sceptical about how, and whether, it would work in practice. The prospect of being assessed by self-advocates, by contrast, triggered considerable anxiety amongst students who feared anomalous marks. However, when discussing actual experiences of being taught and assessed by self-advocates, students were overwhelmingly positive.

\section{Journeys from discomfort to comfort around disability: 'self-advocates were so confident and at ease with themselves that they encouraged the whole class to let go of their inhibitions'}

Many participants described journeys from discomfort to comfort around disability over the course of the module. Language was initially a source of anxiety for some:

Anonymous 6: Initially, I was a little bit concerned. I feared that I would say something without thinking (or without the contemporary/politically correct terms) and offend the self-advocates and shame myself.

For some, anxieties around being politically correct and avoiding causing offense were particularly acute when making inclusive presentations, which were assessed by the self-advocates. For example:

Anonymous 18: Again, we were conscious not to offend anyone during presentations.and

Anonymous 6: I found that the real difficulty was agreeing on ideas that were respectful and appropriate. There was a great fear in over-simplifying the material and disrespecting the intellect of the advocates, or outweighing facts with humour.

Certain topics covered also generated discomfort. For example, one student found being taught about eugenics and abuse within intellectual disability services by people with intellectual disabilities to be a discomforting but powerful pedagogical experience:

Anonymous 11: I found the first class quite difficult, as we were discussing the history of abuse/eugenics. This material was very distressing to hear from one who could have been a victim of abuse (if they were born a few decades earlier). It was quite upsetting. In saying that, it made the material all the more effective and powerful.

While students reported moments of awkwardness many more described how the self-advocates' openness, informality and humour created a warm and lively teaching environment:

Anonymous 15: They were all very funny. 
and

Anonymous 2: The classes were lively and fun to attend and completely different to other lectures and that was $100 \%$ welcomed and appreciated.

Several students valued the self-advocates' perceived unselfconsciousness, and frequent disregard for social and pedagogical conventions.

Focus group participant 1: It's almost like they just don't care. Like that's the beauty, I think.

Everyone: Yeah

Focus group participant 1: They don't have all this...

Focus group participant 2: Social graces?

Focus group participant 1: That I have and all this 'Oh who'll be looking at me and will I talk funny and will they like what I say'. They just stand up there and they're just themselves and I think it's so refreshing

Focus group participant 3: Oh, I love that!

This informality and perceived unselfconsciousness, in-turn, encouraged students to lower their inhibitions in class discussions and role plays:

Anonymous 6: It was such a fun and lively way to learn, and the self-advocates were so confident and at ease with themselves that they encouraged the whole class to let go of their inhibitions. I've never seen our class so confident and imaginative in role play and presenting.

Students enjoyed being assessed by self-advocates for similar reasons. To begin, many felt the mode of assessment (accessible presentations) and the self-advocates' warmth and informality encouraged students to be creative and have fun. For example:

Anonymous 6: The assessment they set- the presentations- were FAB! As they encouraged us to get creative and adventurous with it. Everyone had fun and actually made entertaining presentations! It was a relaxed and non-judgemental atmosphere on presentation day too.

Finally, students described how being taught and assessed by adults with intellectual disabilities eventually allowed them to become more comfortable and less self-conscious when interacting with people with disabilities:

Anonymous 2: I had not known many people with an intellectual disability (...) and, being honest, I did not know how to speak to someone with a disability. Now I know that I can just speak to someone with a disability the same way that I would speak to any other person.

and 
Anonymous 6: The self-advocates were amazing at facilitating class discussions and allowing everyone to speak without fear. Thanks to them, I now feel a lot more comfortable about discussing intellectual disability.

Indeed, some came to see the class as a safe space to have this type of discussion:

Anonymous 4: I previously worked with people who had several forms of disability but was never in a safe space where I could have a discussion.

To summarise, students described initial discomfort in their interactions with self-advocates. Several reported awkwardness around language and a fear of using politically incorrect terminology in class or patronising language in presentations. Some topics covered by self-advocates also evoked discomfort. This said many students described how the self-advocates' openness, informality and humour created a safe space where students felt increasingly comfortable and disinhibited and were able to be creative and have fun while being assessed. By the end of the module, experiences such as these meant many students felt more confident and comfortable around disabled people.

\section{Valuing the subversion of traditional power relations: 'god for once in their life, they have the power and we don't'}

Many of the students pointed to ways the experience of being taught by self-advocates subverted traditional power relations in interesting and productive ways. One respondent pointed to the significance of a university, and the academics within it, taking people with intellectual disabilities seriously:

Anonymous 12: I thought it showed a good, positive sign in the attitudes of lecturers and people in authority towards people with intellectual disabilities.

One saw the self-advocates control over assessment as being particularly significant in moving beyond tokenism and changing power relations in significant ways:

Focus group participant 1: I thought now that's really giving full ownership (...). They were teaching about intellectual disability and they were going to mark some intellectual disability [essays] and I thought (...) that was really brilliant for the guys. For [the lecturers without disabilities] to give them full responsibility. (...) That's deadly.

Student accounts of the experience of assessment also seem to illustrate the disruption of traditional power relations. For example, one student described valuing the wisdom of their markers with intellectual disabilities and desiring their approval: 
Focus group participant 3: It felt really good. It was like, yeah, they're really looking at our work. They're really taking it seriously. They're really gonna view us for who we are. Do you know that kind of way?

Some participants saw the interactions between lecturers with and without disabilities as being significant in disrupting traditional power hierarchies and modelling egalitarian and non-patronising relations:

Focus group participant 1: I thought [the academic lecturer's] respect and interaction with all of them was highly honed. (...) I noticed at one stage they (the self-advocates) were slagging him. So I thought (...) that was a testimony to him and to them that they were all equals.

Multiple participants saw the initiative as producing powerful roles for people with intellectual disabilities. For example:

Anonymous 5: It provided the co-lectures with a great deal of empowerment.

This empowerment was understood to be particularly important by others, given that people with intellectual disabilities are often denied power:

Focus group participant 1: The other thing as well which really struck me was (...) 'God for once in their life, they have the power and we don't' (...). So I kind of thought that was really, really good to give them that.

Others noted that the experience of teaching and the power that came with it, in-turn, seemed to bolster the self-advocates' confidence and competence:

Focus group participant 3: You could actually see the confidence as well change.

Focus group participant 2: Oh my God, yeah.

Focus group participant 3: You know sometimes when they delivered a really good set of slides, like they were thrilled, chuffed. You know what I mean? Walking away and high fiving.

Focus group participant 4: Yeah, they took it really seriously.

Focus group participant 2: They did

Focus group participant 4: And I think as well cause like you said they were given full responsibility and they realised that there was confidence in them. So they said 'Right, we're gonna do it, and we'll do our best'. And they took it really seriously.

Finally, one participant pointed to the fact that some of the power relations structuring this course - people with disabilities teaching caring professionals - should be normal rather than exceptional:

Focus group participant 4: It just upset me that it's just so different for them, like I don't see why it should be. And the fact that they have to- you know that they have to prove themselves so much more. (...) I was obviously really happy that they had the opportunity but I remember having mixed feelings that there was 
such a big deal made out of it, when really it's just really a girl standing in front of us (...) teaching us and telling us her experiences.

To summarise, students valued how the initiative gave power to people with intellectual disabilities and modelled egalitarian power relations. They pointed to the control self-advocates had over assessments as evidence of a move beyond tokenism. They also noted how the power given to selfadvocates seemed to bolster their confidence and competence. Finally, some felt that the power relations structuring this module should be commonplace rather than remarkable.

\section{Valuing and problematizing teaching based on experiential knowledge: 'the best people to assess on something like that are the people that are actually living it'}

Students reported looking forward to learning about the lived experience of self-advocates. For example:

Anonymous 16: I thought that it would be very beneficial to hear from people who have lived and experienced discrimination and difficulties surrounding their disability.

One felt this type of learning was particularly relevant as they had little prior experience of intellectual disability:

Anonymous 14: As someone who does not know anyone personally who has an intellectual disability, I thought it would be beneficial in that sense.

Most students described learning about the lived experience of self-advocates as a valuable and powerful pedagogical experience:

Anonymous 5: I really felt like I was given the knowledge and expertise directly from the person themselves. They are the people who understand and know best about services and the appropriate ways to work with people with intellectual disabilities.

Some spoke about how learning about the lived experiences of self-advocates brought disability theory to life for social workers in training:

Focus group participant 4: We have so many lovely theories and, yeah, they are nice, and they probably help us learn on a very expansive level. But (.) we're not going to go into a job to sit in front of a theory. (...) We're sitting in front of a person. (... ) So it's really important, I think.

Regarding being assessed by self-advocates, some students felt that their experiential knowledge made them ideal markers. For example:

Anonymous 5: Adults with intellectual disabilities have the knowledge and expertise to assess our presentations and therefore it will provide more accurate results.

and: 
Focus group participant 4: I mean and the best people to assess on something like that are the people that are actually living it.

While most students pointed to the value of the self-advocates' experiential knowledge and personal stories, a small number of students were less enthusiastic about the self-advocates presenting academic content and theoretical material from easy to read PowerPoint slides. For example:

Anonymous 3: I didn't enjoy them reading off the slides, when they talked freely it was a lot better.

Finally, one student suggested that, rather than self-advocates presenting academic content in a simplified way, the academic lecturers should cover this in a more thorough manner:

Anonymous 3: I think (the full-time lecturers) should do the academic bits (e.g. eugenics) because we are not going deep enough into the topic. Then the colectures could talk about their experiences or what it means in their life.

In summary, students valued the experiential knowledge of self-advocates and recognised this knowledge as constituting a form of expertise. They felt that the lived experience of self-advocates helped bring dry disability theory to life and qualified them to act as markers. On the other hand, some were less keen on the self-advocates' presentation of academic and theoretical material.

\section{Increasing empathy with people with intellectual disabilities: 'I have learned to see things from their perspectives'}

Many participants felt the experience of being taught by self-advocates led to greater empathy with people with intellectual disabilities. For example:

Anonymous 13: I have learned to see things from their perspectives and understand their rights and their wishes. It has enhanced my understanding of what life is like for the self-advocates.

One felt a standard disability module could not increase empathy in the same way:

Anonymous 8: It eliminated any preconceptions. We came to see them as people rather that an ID, which can't happen in a regular lecture.

Some felt their increased empathy - in this case around how it feels to be pathologised - would improve their professional practice:

Anonymous 16: Learning about how they felt when faced with the medical model helped me understand how it feels for them and how to work with them in a way that is inclusive. This will be very helpful to me in my future career. 
One described increased empathy regarding the complex decisions people with intellectual disabilities must make around identification and whether to accept or reject the pathological labels they are given:

Focus group participant 4: I'd be like: 'No, yous are just normal. I wouldn't even want to think of yous as disabled'. But then they came back with (...) 'If I'm not considered say disabled, I may not get this money [a disability allowance] that I count on'. And then I was like: 'Wow, yeah, I never thought of that'.

Others pointed to increased empathy around disability-based discrimination: Anonymous 16: It is okay to read about how people with intellectual disabilities are discriminated against but until you hear real life stories from the people who experienced it, it's not the same.

Finally, regarding the assessment process, students described how planning presentations for adults with intellectual disabilities facilitated greater empathy around the importance of accessibility and accessible information. For example:

Anonymous 12: It made us think more about how we are presenting the information and become more aware of how to present the info accessibly.

and

Anonymous 1: This was the ultimate challenge! Presenting in such a way - to show elements of understanding - to use language and visuals that would entertain, inform and impress!

In summary, students felt the module facilitated increased empathy with people with disabilities in ways that a traditional module could not. They pointed to an increased understanding of what it was like to be pathologized, to experience discrimination, to identify as disabled, as well as of the importance of accessibility and accessible information.

\section{Increased appreciation of the capacities of people with intellectual disabilities: 'I think we all look at people with disabilities different now'}

Students described the experience as deepening their appreciation of what people with intellectual disabilities can do and can contribute. For example:

Anonymous 9: I think this module beautifully demonstrated what people with ID have to bring to the world.

One student, who worked in the disability field, felt their increased appreciation of the capabilities of people with intellectual disabilities would inspire them to aim higher in supporting service users to achieve goals:

Focus group participant 2: I think we all look at people with disabilities different now. If we do happen to go out into the disability sector and, you know, if I was to go back to (...) where I worked before. (...) I would be referencing these people 
[the self-advocates] all of the time, saying 'You have the potential to do this'. Do you know what I mean? (...) If it's something that they wanted to do, there's nothing going to stop you.

For another - who has a child with Down syndrome - the experience prompted her to think about what else her child might be capable of:

Focus group participant 1: I was looking in the mirror a bit. (...) I suppose I did go 'God, I should be doing this and I should be doing that' and 'God, maybe he's more capable?'

To summarise, students described the module as bringing about an increased appreciation of what people with disabilities can do and contribute. For some, who work or live with people with intellectual disabilities, the module inspired them to revise their ideas regarding their capacities and to aim higher in helping them to achieve their dreams.

\section{Discussion}

In keeping with our inclusive methodology, in addition to the existing literature, our discussion is informed by insights and reactions from our group of researchers with and without intellectual disabilities.

Regarding students' reactions to the prospect of being taught by selfadvocates with intellectual disabilities, the positivity reported by students in this study is in keeping with the existing literature on experiences of inclusive teaching (Curran 1997; Turner et al. 2000; Costello and Horne 2001). Concerns about tokenism - which some participants in this study shared are also found in previous literature (Rhodes 2012; Simons et al. 2007; Higgins et al. 2011; Forrest et al. 2000; Happell et al. 2014; Bollard, Lahiff, and Parkes 2012). On the other hand, student anxiety around assessment is not frequently discussed in the literature, perhaps because the initiatives described tend to relate more to teaching rather than assessment. In our team's discussions it emerged that some self-advocates also felt anxiety around assessment, specifically about taking on this responsibility: I felt scared before doing the marking. When I found out [about that] I felt a good sense of responsibility. Another pointed out that students' fears were illfounded given the quality of their work: They didn't need to be nervous. Some of the presentations were outstanding. The story about the princess [one of the presentations that satirised Irish consent laws within the format of a fairy tale]? How incredible that presentation was, how much work they put into it. Meanwhile, an academic member of the team suggested that the fact that marks awarded by academics and self-advocates tended to correlate closely also indicated that students' initial fears did not materialise in practice.

The initial feelings of discomfort around disability, and people with disabilities, reported by students chime with some of the existing literature on 
including service users in teaching. Reports of student anxiety or embarrassment, for example, are found in several studies (Towle et al. 2010; Ottewill et al. 2006; Costello and Horne 2001). However, the specific fears, regarding discussion of sensitive topics and discomfort around language, that emerged in our analysis do not appear as frequently in this literature (a partial exception being Duffy, Das, and Davidson 2013). In our team's discussions of students fears of upsetting or causing offense, it emerged that the selfadvocates are, perhaps, not as sensitive as their students feared. One felt they should not be shielded from topics (such as eugenics) that could be deemed upsetting: 'We have the right to be upset or offended like everyone else. Don't try to protect us.' Another felt student anxieties around language reflected problematic levels of political correctness in society generally: 'People worry too much about these things today. Everybody worries about that these days'. Finally, one self-advocate had practical ideas about how anxiety could be alleviating in future initiatives of this type. Instead of starting the module with disturbing content (institutionalisation and eugenics), as we did, they suggested: 'We should have done fun stuff at the beginning to make the awkwardness go away'. This may be an excellent suggestion, given that students pointed to the self-advocates' humour, irreverence, and lack of inhibitions as key to their growing sense of comfort in talking about disability and interacting with people with disabilities. Overall, the journeys from discomfort to comfort described in our data, add to existing evidence that including representatives of client groups in teaching health and social care professionals can foster increased comfort and confidence amongst students (Maughan, Finlay, and Webster 2001).

The theme of empowerment, which emerged in this study, occurs frequently within the existing literature and is treated both as a reason for including service users and a consequence of including service users (Towle et al. 2010; Tyler 2006; Bollard, Lahiff, and Parkes 2012). As mentioned previously, concerns regarding tokenism are also common in the literature. A novel finding here is that students took interactions between lecturers with and without disabilities, as well as the control that self-advocates had over assessments, as evidence that the power held by self-advocates was genuine and went beyond tokenism. In our discussion of this theme some self-advocates agreed with students' observations regarding power. One suggested: 'I felt a good sense of empowerment'. Meanwhile, several corroborated student's observations that taking on a powerful role seemed to bolster their confidence and competence. One observed that: I used to find speaking to lots of people scary. I feel more confident with big crowds after the teaching. Another recalled a specific incident during the module, where the nondisabled lecturer had to leave a lecture and left the self-advocates alone to teach, as feeling particularly empowering. Overall, our findings echo existing 
work that suggests inclusion in teaching university students empowers service users, but they also suggest that students are cognisant of and value this empowerment if they perceive this to be genuine.

In relation to valuing experiential knowledge, our findings add to existing evidence that, in addition to policymakers, students recognise the value of lived experience (see, for example, Turner et al. 2000). Moreover, in this study, students acknowledged lived experience as a form of expertise that qualifies self-advocates to both teach, and assess, topics related to disability in a university setting. Interestingly, when discussing this aspect of our findings, self-advocates expressed more nuanced views concerning their expertise. They suggested that, ultimately, they were only experts on their personal experiences and problematised the notion that they could speak for others with disabilities. This said, some acknowledged that having a disability can provide a degree of insight into disabled experience in general: 'We would be more tuned in than people who don't have a disability'. A new issue that emerged in this study in relation to self-advocates' expertise relates to their use of PowerPoint notes as mnemonic devices. Certain students' opposition to this provoked considerable discussion in our analysis meetings, with selfadvocates tending to see PowerPoint slides as legitimate and necessary assistive technologies: 'I needed the support. It made me feel safer'. Another new issue to emerge is the question of whether self-advocates should be involved in presenting all the material covered (including complex theoretical content) or whether academics should cover complex content in an academic style, leaving self-advocates to illustrate this content with stories about their experiences. In our discussion of this question, self-advocates favoured completely accessible lecture content - even if this meant compromising academic complexity - to ensure everyone was involved and understood what was going on: 'If there was more detail in the slides, we wouldn't understand it.' The academic present agreed with the self-advocates. Presenting material in a traditional academic style would undermine one of the central aims of the module: to model inclusiveness and accessibility. The academic also pointed out that, at the end of each lecture, students were provided with a reading list of academic sources, designed to allow a deeper engagement with the topics covered in lectures. This said, the tension between academic depth and accessibility which emerged in our data, is something that those planning future initiatives may wish to consider.

The reports of students feeling increased empathy with people with intellectual disabilities that we present in this paper again chime with claims found in the existing literature (Biswas, Raju, and Gravestock 2009; Tanner et al. 2017). A new finding here is that increased empathy is found in areas relating to disability specifically (e.g. around labelling and discrimination). Another novel finding is that assessments in the form of accessible 
presentations can encourage students to think about the perspectives of their examiners with disabilities and, in doing so, increase empathy regarding the importance of accessible information. In our discussion of these findings, self-advocates said they were happy to have bolstered students' empathy: 'It's good for them to take a walk in our shoes, then take a look at themselves'. They were also glad to have prompted students to think about providing information for people with a range of abilities: 'Giving information in lots of different formats is important'.

Finally, student reports of increased appreciation of the capacities of their disabled lecturers in this study are echoed in Ward et al.'s (2016) exploration of students' experiences of being taught by a man with profound and multiple disabilities. An additional finding of this project is that being taught and examined at university level by adults with intellectual disabilities inspired students who support these adults (either professionally or in a parental capacity) to 'aim higher' in setting life goals. Self-advocates felt this was very significant, pointing to a tendency amongst their peers (and their peers' parents) to accept disability specific services for school leavers with disabilities rather than aiming to participate in mainstream university or to work in valued mainstream professions. In short, self-advocates were glad to be an inspiration to others.

\section{Conclusion}

In this paper we have presented and analysed university students' experiences of being co-taught and co-examined by adults with intellectual disabilities. While there have been many calls for, and attempts to, include service users in general in the education of social and health care professionals, there is little existing literature that details adults with intellectual disabilities co-designing, co-lecturing and co-assessing an entire module. Likewise, there is a dearth of research exploring how students experience this type of initiative. As such, we feel it is significant to report that initiatives like this can work and can be very popular with university students. Moreover, in this study at least, inclusion of adults with intellectual disabilities in teaching and assessing university students was associated with a range of benefits including greater comfort around disability, more empathy with those with disabilities, and increased appreciation of what people with intellectual disabilities are capable of. Our hope in presenting these findings is that they might encourage university lecturers across a range of social and health care professions to include adults with intellectual disabilities in both teaching and assessing students. Even better, they might be useful to people who would like to take inclusion further still. For example, by developing a module that is taught and assessed by individuals with intellectual disabilities as 
sole lecturers and sole assessors, with academics providing only background support.

\section{Disclosure statement}

No potential conflict of interest was reported by the authors.

\section{ORCID}

Edurne Garcia Iriarte (D) http://orcid.org/0000-0002-8155-1263

\section{References}

Bane, G., M. Deely, B. Donohoe, M. Dooher, J. Flaherty, E. G. Iriarte, R. Hopkins, et al. 2012. "Relationships of People with Learning Disabilities in Ireland." British Journal of Learning Disabilities 40 (2): 109-122. doi:10.1111/j.1468-3156.2012.00741.x.

Biswas, A. B., L. B. Raju, and S. Gravestock. 2009. "Training in Partnership: Role of Service Users with Intellectual Disability and Carers." Psychiatric Bulletin 33 (11): 429-432. doi: 10.1192/pb.bp.108.020701.

Bollard, M., J. Lahiff, and N. Parkes. 2012. "Involving People with Learning Disabilities in Nurse Education: Towards an Inclusive Approach." Nurse Education Today 32 (2): 173-177. doi:10.1016/j.nedt.2011.10.002.

Boxall, K., I. Carson, and D. Docherty. 2004. "Room at the Academy? People with Learning Difficulties and Higher Education." Disability \& Society 19 (2): 99-112.

Braun, V., and V. Clarke. 2006. "Using Thematic Analysis in Psychology." Qualitative Research in Psychology 3 (2): 77-101. [Database] doi:10.1191/1478088706qp063oa.

Charlton, J. 1998. Nothing about Us without Us: Disability Oppression and Empowerment. Berkeley, CA: University of California Press.

CORU. 2016. Criteria and Standards of Proficiency for Education and Training: Guidelines for Education Providers. Dublin: CORU.

Costello, J., and M. Horne. 2001. "Patients as Teachers? An Evaluative Study of Patients' Involvement in Classroom Teaching." Nurse Education in Practice 1 (2): 94-102. doi:10. 1054/nepr.2001.0014.

Curran, T. 1997. "Power, Participation and Post Modernism: User and Practitioner Participation in Mental Health Social Work Education." Social Work Education 16 (3): 21-36. doi:10.1080/02615479711220221.

Duffy, J., C. Das, and G. Davidson. 2013. "Service User and Carer Involvement in Role-Plays to Assess Readiness for Practice." Social Work Education 32 (1): 39-54. doi:10.1080/ 02615479.2011.639066.

Forrest, S., I. Risk, H. Masters, and N. Brown. 2000. "Mental Health Service User Involvement in Nurse Education: Exploring the Issues." Journal of Psychiatric and Mental Health Nursing 7 (1): 51-57. doi:10.1046/j.1365-2850.2000.00262.x.

Fox, J. 2011. "'The View from Inside': Understanding Service User Involvement in Health and Social Care Education." Disability \& Society 26: 169-177.

García Iriarte, E., P. O'Brien, and D. Chadwick. 2014. "People with Intellectual Disabilities in Research Teams." Journal of Policy and Practice in Intellectual Disabilities 11: 149-157.

Happell, B., L. Byrne, C. Platania-Phung, S. Harris, J. Bradshaw, and J. Davies. 2014. "LivedExperience Participation in Nurse Education: Reducing Stigma and Enhancing 
Popularity." International Journal of Mental Health Nursing 23 (5): 427-434. doi:10.1111/ inm.12077.

Higgins, A., G. Maguire, M. Watts, M. Creaner, E. Mccann, S. Rani, and J. Alexander. 2011. "Service User Involvement in Mental Health Practitioner Education in Ireland." Journal of Psychiatric and Mental Health Nursing 18 (6): 519-525. doi:10.1111/j.1365-2850.2011. 01698.x.

IASSW. 2004. Global Standards for the Education and Training of the Social Work Profession. Adelaide: IASSW.

Kelly, D., and G. Wykurz. 1998. "Patients as Teachers: A New Perspective in Medical Education." Education for Health 11 (3): 369-377.

Kramer, J., J. Kramer, E. García-Iriarte, and J. Hammel. 2011. "Following through to the End: The Use of Inclusive Strategies to Analyse and Interpret Data in Participatory Action Research with Individuals with Intellectual Disabilities." Journal of Applied Research in Intellectual Disabilities 24: 263-273.

Maughan, T. S., I. G. Finlay, and D. J. Webster. 2001. "Portfolio Learning with Cancer Patients: An Integrated Module in Undergraduate Medical Education." Clinical Oncology (Royal College of Radiologists (Great Britain)) 13 (1): 44-49. doi:10.1053/clon.2001.9213.

Nind, M. 2017. "The Practical Wisdom of Inclusive Research." Qualitative Research 17 (3): 278-288. doi:10.1177/1468794117708123.

Ottewill, R., S. Demain, C. Ellis-Hill, C. H. Greenyer, and J. Kileff. 2006. "An Expert PatientLed Approach to Learning and Teaching: The Case of Physiotherapy." Medical Teacher 28 (4): e120-e126. doi:10.1080/01421590600726698.

Patton, M. 2015. Qualitative Research \& Evaluation Methods. Thousand Oaks, CA: Sage.

Repper, J., and J. Breeze. 2007. "User and Carer Involvement in the Training and Education of Health Professionals: A Review of the Literature." International Journal of Nursing Studies 44 (3): 511-519. doi:10.1016/j.ijnurstu.2006.05.013.

Rhodes, C. A. 2012. "User Involvement in Health and Social Care Education: A Concept Analysis." Nurse Education Today 32 (2): 185-189. doi:10.1016/j.nedt.2011.11.012.

Salmon, N., E. García-Iriarte, B. Donohoe, L. Murray, G. Singleton, M. Barrett, and M. Dillon. 2019. "Our Homes: An Inclusive Study about What Moving House Is Like for People with Intellectual Disabilities in Ireland." British Journal of Learning Disabilities 47 (1): 19-28. doi:10.1111/bld.12251.

Simons, L., S. Tee, J. Lathlean, A. Burgess, L. Herbert, and C. Gibson. 2007. "A Socially Inclusive Approach to User Participation in Higher Education." Journal of Advanced Nursing 58 (3): 246-255. doi:10.1111/j.1365-2648.2007.04216.x.

Spencer, J., W. Godolphin, N. Karpenko, and A. Towle. 2001. Can Patients Be Teachers? Involving Patients and Service Users in Healthcare Professionals' Education. London: The Health Foundation.

Stickley, T., and T. Bassett. 2007. Teaching Mental Health. London: John Wiley and Sons.

Strnadova, I., and J. Walmsley. 2018. "Peer-Reviewed Articles on Inclusive Research: Do CoResearchers with Intellectual Disabilities Have a Voice?" Journal of Applied Research in Intellectual Disability 31: 132-141.

Tanner, D., R. Littlechild, J. Duffy, and D. Hayes. 2017. "Making It Real: Evaluating the Impact of Service User and Carer Involvement in Social Work Education." British Journal of Social Work 42: 467-486.

Towle, A., C. Farrell, M. E. Gaines, W. Godolphin, G. John, C. Kline, B. Lown, P. Morris, J. Symons, and J. Thistlethwaite. 2016. "The Patient's Voice in Health and Social Care Professional Education: The Vancouver Statement." International Journal of Health Governance 21 (1): 18-25. doi:10.1108/JHG-01-2016-0003. 
Towle, A., L. Bainbridge, W. Godolphin, A. Katz, C. Kline, B. Lown, I. Madularu, P. Solomon, and J. Thistlethwaite. 2010. "Active Patient Involvement in the Education of Health Professionals." Medical Education 44 (1): 64-74. doi:10.1111/j.1365-2923.2009.03530.x.

Turner, P., F. Sheldon, C. Coles, B. Mountford, R. Hillier, P. Radway, and B. Wee. 2000. "Listening to and Learning from the Family Carer's Story: An Innovative Approach in Interprofessional Education." Journal of Interprofessional Care 14 (4): 387-395.

Tyler, G. 2006. "Addressing Barriers to Participation: Service User Involvement in Social Work Training." Social Work Education 25 (4): 385-392. doi:10.1080/02615470600593394.

Walmsley, J., I. Strnadova, and K. Johnson. 2018. "The Added Value of Inclusive Research." Journal of Applied Research in Intellectual Disabilities 31 (5): 751-759. doi:10.1111/jar. 12431.

Ward, N., Raphael, C., Clark, M. \& Raphael, V. (2016). "Involving people with profound and multiple learning disabilities in social work education: building inclusive practice." Social Work Education, 3 (8): 918-932, doi:10.1080/02615479.2016.1239705

Warren, J. 2007. Service User and Carer Participation in Social Work. Exeter: Learning Matters.

Wood, J., and J. Wilson-Barnett. 1999. "The Influence of User Involvement on the Learning of Mental Health Nursing Students." Journal of Research in Nursing 4 (4): 257-270. doi: $10.1177 / 136140969900400403$. 